\title{
Fluoxetine improves minor depressive disorders
}

Judd LL, Rapaport MH, Yonkers KA, et al. Randomized, placebo-controlled trial of fluoxetine for acute treatment of minor depressive disorder. Am J Psychiatry 2004;161:1864-71.

\section{Is fluoxetine effective and safe for minor depressive disorders?}

\section{METHODS}

Design: Randomised controlled trial.
Allocation: Concealed.
Blinding: Double blind.
$\begin{aligned} & \text { Selting: Three hospitals in the USA. } \\ & \text { Patients: } 162 \text { people (mean age } 43.5 \text { years; range 18-72) with } \\ & \text { minor depressive disorder (diagnosed with an amended version } 12 \text { weeks. } \\ & \text { of the National Institute of Mental Health Diagnostic Interview } \\ & \text { Schedule (DIS)). Eligible participants were English speaking, } \\ & \text { healthy, with normal physical examination and laboratory results } \\ & \text { (complete blood count, urine analysis and toxicology screen, and } \\ & \text { hepatic and renal function tests). Main exclusions: major } \\ & \text { depressive or dysthymic disorder; recent bereavement; serious } \\ & \text { risk of suicide; history of substance abuse; axis } 1 \text { disorder; } \\ & \text { bipolar disorder; borderline or antisocial personality disorder; } \\ & \text { psychotic disorder; schizophrenia; psychotropic drug use; serious } \\ & \text { medical condition; seizure disorder; previous participation in a } \\ & \text { fluoxetine study; previous adverse reactions with fluoxetine; } \\ & \text { previous non-response to fluoxetine. } \\ & \text { Intervention: Placebo for } 4 \text { weeks followed by fluoxetine } \\ & \text { (10 mg/day) or placebo for } 2 \text { weeks. For the remaining } \\ & 10 \text { weeks participants received fluoxetine (20 mg/day) or } \\ & \text { placebo. }\end{aligned}$
Outcomes: Primary outcome: depressive symptom severity
(Inventory of Depressive Symptomatology scores). Secondary
outcomes: depressive symptom severity (Beck Depression
Inventory score; 17-item, 21 -item, and 28-item Hamilton
Depression Rating Scale; Clinical Global Impression severity
scale score), psychosocial functioning (Global Assessment of
Functioning Scale score), and adverse events.
$\begin{aligned} & \text { Patient follow up: } 12 \text { weeks; } 118 / 162 \text { (73\%) completed } \\ & \text { treatment. }\end{aligned}$

\section{MAIN RESULTS}

Fluoxetine significantly reduced depression compared with placebo at 12 weeks (mean Inventory of Depressive Symptomatology score: 12.3 with fluoxetine $v 15.6, \mathrm{p}<0.02$; mean Beck Depression Inventory score: 8.6 with fluoxetine $v 12.0$ with placebo, $\mathrm{p}<0.02$; mean Hamilton Depression Rating Scale score: 17-item scale 7.1 with

For correspondence: Dr $\mathrm{L} \mathrm{L}$ Judd, Department of Psychiatry, University of California, San Diego, 9500 Gilman D, La Jolla, CA 92093-0603, USA; liudd@ucsd.edu

Sources of funding: NIMH grants MH-30914, MH-49671, MH-30915, MH53799 and MH-01648-01; the Roher Fund of the University of California, San Diego; and an unrestricted investigator-initiated contract from Eli Lilly and Co. fluoxetine $v 8.1$ with placebo, $\mathrm{p}<0.05,21$-item scale 7.4 with fluoxetine $v 8.5$ with placebo, $\mathrm{p}=0.04$; mean Clinical Global Impression Severity Scale: 2.1 with fluoxetine $v 2.5$ with placebo, $\mathrm{p}=0.002$ ). However, there was no significant difference between fluoxetine and placebo in psychosocial functioning (mean Global Assessment of Functioning Scale score: 74.7 with fluoxetine $v 73.0$ with placebo, $\mathrm{p}=0.10)$. Overall, adverse events were similar between treatment groups (mean number of adverse events: 5.2 with fluoxetine $v 4.6$ with placebo, $\mathrm{p}=0.15)$, although fluoxetine increased insomnia compared with placebo (absolute risk 24.7\% with fluoxetine $v 12.4 \%$ with placebo, $\mathrm{p}<0.05$ ).

\section{CONCLUSIONS}

Fluoxetine is effective and safe for the treatment of minor depressive disorder.

\section{NOTES}

The authors note that the standardised depression rating scales used were validated for major and not minor subthreshold depression. People with known non-response to fluoxetine were excluded from this study, so results may not apply to an unselected population.

\section{Commentary}

Trertion here has been longstanding uncertainty about the value of antidepressant treatment in milder depressive states-that is, depressive conditions not possessing the required number of symptoms to meet DSM-IV criteria for major depressive episode. In DSM-IV, such conditions can be classified as minor depressive disorder, while in ICD-10 the term mild depressive episode is used. The latter usage has been adopted in the recent guidelines on the treatment of depression issued by the UK's National Institute for Clinical Excellence (NICE). ${ }^{1}$ The NICE guidelines suggest that antidepressant medication should not be used as initial treatment in mild depression because of the lack of evidence of efficacy and the uncertain risk-benefit ratio.

The well conducted study by Judd et al provides a convincing demonstration of the statistical efficacy of fluoxetine $(20 \mathrm{mg}$ daily) in minor depression, but the question is how far fluoxetine treatment produces real clinical benefit in this population. For example, at the end of treatment the mean score on the standard 17-item Hamilton Rating Scale for Depression (HAM-D) in the fluoxetine treated group was only one point better than that of the placebo group. In addition, fluoxetine treatment was not associated with improvements in psychosocial function. On the other hand, on the Clinical Global Impression scale, $40.5 \%$ of the fluoxetine treated patients were "normal, not at all depressed", at the end of treatment compared with $24.1 \%$ of placebo treated subjects - this seems a worthwhile difference.

Overall, it seems likely that appropriately designed trials can detect significant effects of antidepressants on mild depressive symptoms but the clinical relevance remains to be demonstrated. "Watchful waiting" or non-pharmacological treatment still seems the best initial management of

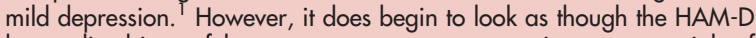
has outlived its usefulness as an outcome measure in treatment trials of depression.

Philip J Cowen, MD, FRCPsych MRC Clinical Scientist, University of Oxford, UK

1 National Institute for Clinical Excellence. Depression: Management of depression in primary and secondary care. National Clinical Practice Guideline, Number 23. NICE, 2004. Available at: www.nice.org.uk/pdf/ cg023fullguideline.pdf (accessed 25 February 2005). 